\title{
Correction to: Chiropractic maintenance care - what's new? A systematic review of the literature
}

Iben Axén ${ }^{1,2^{*}}$, Lise Hestbaek ${ }^{3,4}$ and Charlotte Leboeuf-Yde ${ }^{5}$

\section{Correction to: Chiropr Man Therap (2019) 27:63 \\ https://doi.org/10.1186/s12998-019-0283-6}

After publication of our article [1] the authors have notified us that their names have been incorrectly tagged.

- Original name tagging:

Axén Iben

Hestbaek Lise

Leboeuf-Yde Charlotte

- Correct name tagging:

Iben Axén

Lise Hestbaek

Charlotte Leboeuf-Yde

The original article has been corrected.

Author details

'Karolinska Institutet, Institute of Environmental Medicine, Unit of Intervention and Implementation Research for Worker Health, Nobels väg 13, 17177 Stockholm, Sweden. ${ }^{2}$ Et Liv I Bevegelse (The Norwegian Chiropractic Research Foundation), Storgt 10a, 0155 Oslo, Norway. ${ }^{3}$ Deptartment of Sport Science and Clinical Biomechanics, Odense, Denmark. ${ }^{4}$ Nordic Institute of Chiropractic and Clinical Biomechanics, Odense, Denmark. ${ }^{5}$ nstitute for Regional Health Research, University of Southern Denmark, Odense, Denmark.
Published online: 28 January 2020

\section{Reference}

1. Axén I, et al. Chiropractic maintenance care - what's new? A systematic review of the literature. Chiropr Man Therap. 2019;27:63. https://doi.org/10 1186/s12998-019-0283-6.

The original article can be found online at https://doi.org/10.1186/s12998019-0283-6

* Correspondence: iben.axen@ki.se

${ }^{1}$ Karolinska Institutet, Institute of Environmental Medicine, Unit of

Intervention and Implementation Research for Worker Health, Nobels väg 13,

17177 Stockholm, Sweden

${ }^{2}$ Et Liv I Bevegelse (The Norwegian Chiropractic Research Foundation), Storgt

10a, 0155 Oslo, Norway

Full list of author information is available at the end of the article

(c) The Author(s). 2020 Open Access This article is distributed under the terms of the Creative Commons Attribution 4.0 International License (http://creativecommons.org/licenses/by/4.0/), which permits unrestricted use, distribution, and reproduction in any medium, provided you give appropriate credit to the original author(s) and the source, provide a link to the Creative Commons license, and indicate if changes were made. The Creative Commons Public Domain Dedication waiver (http://creativecommons.org/publicdomain/zero/1.0/) applies to the data made available in this article, unless otherwise stated. 